\title{
Autoimmune encephalitis following ChAdOx1-S SARS-CoV-2 vaccination
}

\author{
Hyeryung Kwon ${ }^{1} \cdot$ Taewon $\operatorname{Kim}^{1}{ }^{10}$
}

Received: 27 August 2021 / Accepted: 25 November 2021 / Published online: 30 November 2021

(c) Fondazione Società Italiana di Neurologia 2021

\section{Introduction}

ChAdOx1-S (Covishield ${ }^{\mathrm{TM} / V a x z e v r i a, ~ A s t r a-Z e n e c a) ~ i s ~ t h e ~}$ main vaccine recommended for mass national immunization program in the Republic of Korea against severe acute respiratory syndrome coronavirus 2 (SARS-CoV-2) and has been administered since March 2021. In addition to mild side effects including pain at the injection site, myalgia, arthralgia, and headache, a serious adverse effect involving vaccine-induced thrombotic thrombocytopenia (VITT) with vascular complications has been reported after administration of this adenovector-based SARS-CoV-2 vaccine [1, 2]. Rarely, autoimmune disease such as Guillain-Barré syndrome (GBS) has also been associated with ChAdOx 1-S vaccination [3,4]. However, as a post-vaccination phenomenon, autoimmune encephalitis (AE) has yet to be reported in the literature. Herein, we describe a patient who developed autoimmune encephalitis the day after the second dose of ChAdOx1-S vaccination with progressive cognitive worsening in a 4-week period.

\section{Case}

A 57-year-old Asian woman affected with hypertension, who had experienced 3-day self-limited myalgia following the first dose of ChAdOx1-S vaccination 2 months prior, reported headache and fever (with a maximum temperature of $38.5^{\circ} \mathrm{C}$ ) the day after the second inoculation of ChAdOx1-S vaccine. Five days later, the patient reported continuing headache and fever, and experienced the firstever generalized convulsive seizure and was admitted to the

Taewon Kim

kimtaewon@catholic.ac.kr

1 Department of Neurology, Incheon St. Mary's Hospital, The Catholic University of Korea, Seoul, Korea, \#56 Dongsu-ro, Bupyeong-gu, Incheon 21431, Korea local hospital. She tested negative for SARS-CoV-2 based on reverse transcription-polymerase chain reaction (PCR) of nasopharyngeal swabs. A cerebrospinal fluid (CSF) study was normal. The PCR analysis of CSF was negative for herpes simplex virus, varicella zoster, and enterovirus. But magnetic resonance imaging (MRI) of the brain demonstrated restricted diffusion along the left insular and mesial temporal cortices with corresponding hyperintensity on fluid-attenuated inversion recovery (FLAIR) without contrast enhancement (Fig. 1). Seizure recurred 6 days later following treatment with levetiracetam $2000 \mathrm{mg}$ /day and oxcarbazepine $900 \mathrm{mg}$ /day. Intravenous acyclovir was administered and maintained for 2 weeks; however, the patient manifested cognitive decline including attention and memory deficits along with gradually worsening dysphasia. She was referred to our hospital, 1 month after initial symptom onset and unable to communicate, except for uttering paraphasic syllables. The patient was bed-ridden. Followup MRI of the brain performed 1 month after the symptom onset demonstrated contrast enhancement along the mesial temporal cortex (Fig. 1), and the follow-up CSF study revealed pleocytosis $(22 / \mu$, lymphocytes $91 \%)$, CSF glucose $114 \mathrm{mg} / \mathrm{dl}$, elevated protein $88.3 \mathrm{mg} / \mathrm{dl}$, and a positive oligoclonal immunoglobulin $\mathrm{G}(\mathrm{IgG})$ band. An autoimmune antibody study involving the CSF against $\mathrm{N}$-methyl-D-aspartate (NMDA) receptors, $\alpha$-amino-3-hydroxy-5-methyl-4isoxazolepropionic acid (AMPA) receptors, leucine-rich glioma-inactivated 1 (LGI1), contactin-associated proteinlike 2 (Caspr2), and $\gamma$-aminobutyric acid (GABA)-B yielded negative results. The repeated PCR analysis of CSF was negative again for herpes simplex virus, varicella zoster, and enterovirus. Serology was negative for Epstein-Barr virus, cytomegalovirus, hepatitis $\mathrm{C}$, and Mycoplasma pneumoniae. Other laboratory studies were unremarkable for connective tissue diseases, vasculitis, and other systemic diseases. SARS-CoV-2 antibody test was negative for nucleocapsid protein and positive for spike protein suggesting the absence of SARS-CoV-2 infection; however, a neutralizing antibody 
Fig. 1 a-b Magnetic resonance imaging (MRI) of the brain demonstrated restricted diffusion along the left insular and mesial temporal cortices. c-d Follow-up MRI of the brain performed 1 month after the symptom onset showed contrast enhancement in the corresponding lesions along the left insular and mesial temporal cortices. e-h One month later, MRI demonstrated the subsidence of the contrast enhancement with the encephalomalacic change in the left temporal lobe

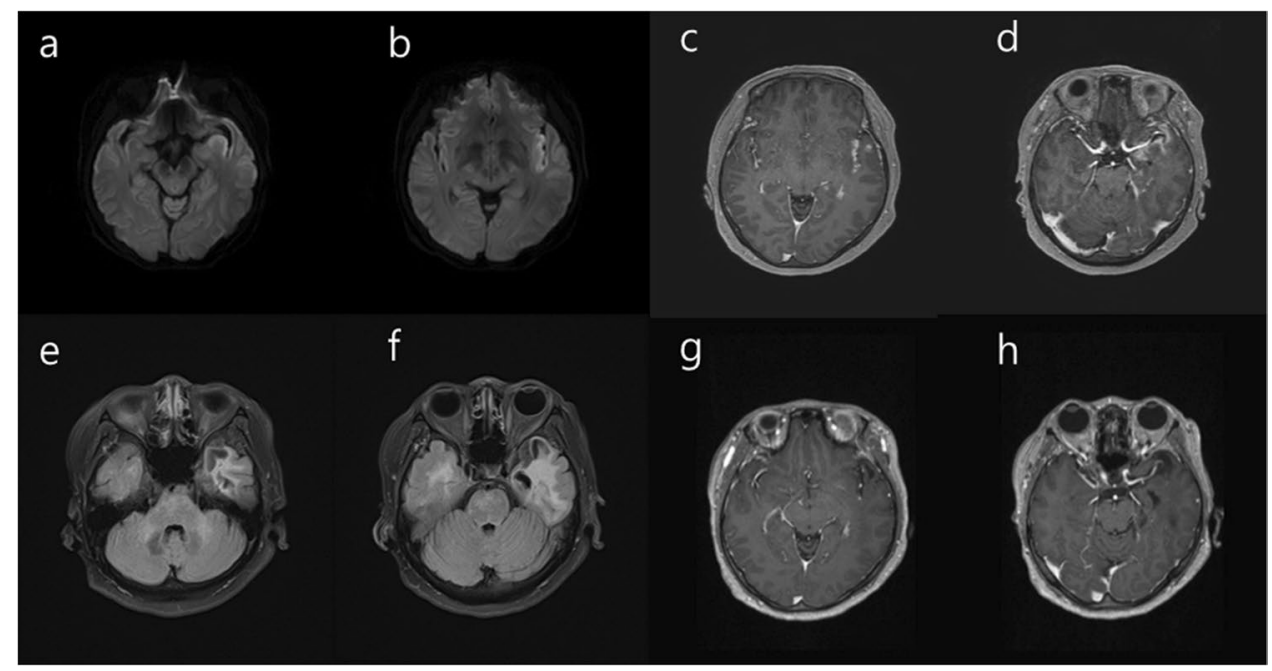

was induced by the vaccination. Antibody to platelet factor 4-polyanion complexes, which was the causal factor for VITT, was not found. Electroencephalogram (EEG) showed intermittent generalized rhythmic delta activity. Based on patient history and laboratory data, a diagnosis of AE related to SARS-CoV-2 vaccination was suspected, and intravenous methylprednisolone $1000 \mathrm{mg} /$ day and immunoglobulin $0.4 \mathrm{~g} / \mathrm{kg} / \mathrm{day}$ were administered and maintained for 5 days. In the absence of clinical recovery for a week, a weekly infusion of rituximab $375 \mathrm{mg} / \mathrm{m}^{2}$ four times was administered. The patient's language function slowly improved substantially following rituximab therapy, but the memory dysfunction hardly improved. Follow-up MRI performed 2 months after the symptom onset demonstrated the subsidence of the contrast enhancement but encephalomalacic change was observed in the left temporal lobe (Fig. 1).

\section{Discussion}

The neurological complications of SARS-CoV-2 infection extend across the entire nervous system including cerebrovascular disorders, post-infectious encephalopathies/ encephalitis, and peripheral nervous system manifestations, typically GBS and its variants. In addition, SARS$\mathrm{CoV}-2$ vaccine also has been reported to be associated with autoimmune disease such as Guillain-Barré syndrome (GBS) $[4,5]$. In this report, we describe a previously healthy patient who developed autoimmune encephalitis the day after the second dose of the ChAdOx1-S vaccine, followed by recurrent seizures and progressive cognitive decline during a 4-week period. Although we evaluated the validity of this report using the Naranjo Adverse Drug Reaction Probability Scale, which corresponded to the total score of four with "possible" causality [6], it cannot be decisively confirmed owing to the lack of any identified direct causative biomarker or antibody. However, considering the low prevalence of autoimmune encephalitis in the general population, an estimated prevalence of 13.7/100,000 [7], as well as the immediate temporal relationship between the vaccination and the development of autoimmune encephalitis in a previously healthy individual, the diagnosis of vaccine-induced AE appears plausible.

Acute disseminated encephalomyelitis (ADEM) was reported after SARS-CoV-2 vaccination using inactivated SARS-CoV-2 (Vero Cells, Beijing Institute of Biological Products Co., Ltd., Beijing, China) [8]. However, our case differs from typical ADEM in several aspects. The initial MRI lesion in our patient was restricted to the medial temporal and insular cortical ribbons excluding white matter or basal ganglia, which are the typical MRI features of limbic encephalitis, while most of ADEM shows several bilateral confluent white matter lesions in both cerebral hemispheres early in the course. Furthermore, the follow-up MRI demonstrated the encephalomalacic changes in the left temporal lobe suggesting axonal destruction rather than demyelinating disease such as ADEM. A positive oligoclonal IgG band and a negative MOG antibody test in our patient also favored the diagnosis of AE rather than ADEM [9, 10].

Recently, one case-series study which investigated patients with SARS-CoV-2 infection and neuropsychiatric symptoms raised the possibility of the central nervous system autoimmunity of the SARS-CoV-2 antibody based on the discovery of anti-SARS-CoV-2 IgG in the CSF [11].

In conclusion, our findings suggest the potential possibility of AE following vaccination with ChAdOx1-S. Further case reports are needed to confirm this association.

Author contribution HK wrote the manuscript. TK supervised the project. 


\section{Declarations}

Ethics approval The authors declare that this single case report has been performed in accordance with the ethical standards laid down in the 1964 Declaration of Helsinki.

Informed consent Informed consent was obtained from the patient and The Institutional Review Board at Incheon St. Mary's Hospital approved this case report.

Conflict of interest The authors declare no competing interests.

\section{References}

1. Blauenfeldt RA, Kristensen SR, Ernstsen SL, Kristensen CCH, Simonsen CZ, Hvas AM (2021) Thrombocytopenia with acute ischemic stroke and bleeding in a patient newly vaccinated with an adenoviral vector-based COVID-19 vaccine. J Thromb Haemost 19(7):1771-1775. https://doi.org/10.1111/jth.15347

2. Schultz NH, Sørvoll IH, Michelsen AE, Munthe LA, LundJohansen F, Ahlen MT, Wiedmann M, Aamodt AH, Skattør TH, Tjønnfjord GE, Holme PA (2021) Thrombosis and thrombocytopenia after ChAdOx1 nCoV-19 vaccination. N Engl J Med 384(22):2124-2130. https://doi.org/10.1056/NEJMoa2104882

3. Maramattom BV, Krishnan P, Paul R, Padmanabhan S, Cherukudal Vishnu Nampoothiri S, Syed AA, Mangat HS (2021) GuillainBarré syndrome following ChAdOx1-S/nCoV-19 vaccine. Ann Neurol 90(2):312-314. https://doi.org/10.1002/ana.26143

4. Allen CM, Ramsamy S, Tarr AW, Tighe PJ, Irving WL, Tanasescu R, Evans JR (2021) Guillain-Barré syndrome variant occurring after SARS-CoV-2 vaccination. Ann Neurol 90(2):315-318. https://doi.org/10.1002/ana.26144

5. Varatharaj A, Thomas N, Ellul MA, Davies NWS, Pollak TA, Tenorio EL, Sultan M, Easton A, Breen G, Zandi M, Coles JP, Manji H, Al-Shahi Salman R, Menon DK, Nicholson TR, Benjamin LA, Carson A, Smith C, Turner MR, Solomon T, Kneen R, Pett SL, Galea I, Thomas RH, Michael BD (2020) Neurological and neuropsychiatric complications of COVID-19 in 153 patients: a UK-wide surveillance study. Lancet Psychiatry 7(10):875-882. https://doi.org/10.1016/s2215-0366(20)30287-x
6. Naranjo CA, Busto U, Sellers EM, Sandor P, Ruiz I, Roberts EA, Janecek E, Domecq C, Greenblatt DJ (1981) A method for estimating the probability of adverse drug reactions. Clin Pharmacol Ther 30(2):239-245. https://doi.org/10.1038/clpt.1981.154

7. Dubey D, Pittock SJ, Kelly CR, McKeon A, Lopez-Chiriboga AS, Lennon VA, Gadoth A, Smith CY, Bryant SC, Klein CJ, Aksamit AJ, Toledano M, Boeve BF, Tillema J-M, Flanagan EP (2018) Autoimmune encephalitis epidemiology and a comparison to infectious encephalitis. Ann Neurol 83(1):166-177. https://doi. org/10.1002/ana.25131

8. Cao L, Ren L (2021) Acute disseminated encephalomyelitis after severe acute respiratory syndrome coronavirus 2 vaccination: a case report. Acta Neurol Belg. 1-3. https://doi.org/10.1007/ s13760-021-01608-2

9. Armangue T, Olivé-Cirera G, Martínez-Hernandez E, Sepulveda M, Ruiz-Garcia R, Muñoz-Batista M, Ariño H, González-Álvarez V, Felipe-Rucián A, Jesús Martínez-González M, CantarínExtremera V, Concepción Miranda-Herrero M, Monge-Galindo L, Tomás-Vila M, Miravet E, Málaga I, Arrambide G, Auger C, Tintoré M, Montalban X, Vanderver A, Graus F, Saiz A, Dalmau J (2020) Associations of paediatric demyelinating and encephalitic syndromes with myelin oligodendrocyte glycoprotein antibodies: a multicentre observational study. Lancet Neurol 19(3):234-246. https://doi.org/10.1016/s1474-4422(19)30488-0

10. Pohl D, Alper G, Van Haren K, Kornberg AJ, Lucchinetti CF, Tenembaum S, Belman AL (2016) Acute disseminated encephalomyelitis: updates on an inflammatory CNS syndrome. Neurology 87(9 Supplement 2):S38-S45

11. Bartley CM, Johns C, Ngo TT, Dandekar R, Loudermilk RL, Alvarenga BD, Hawes IA, Zamecnik CR, Zorn KC, Alexander JR, Wapniarski AE, DeRisi JL, Francisco C, Nash KB, Wietstock SO, Pleasure SJ, Wilson MR (2021) Anti-SARS-CoV-2 and autoantibody profiles in the cerebrospinal fluid of 3 teenaged patients with COVID-19 and subacute neuropsychiatric symptoms. JAMA Neurol. https://doi.org/10.1001/jamaneurol.2021.3821

Publisher's note Springer Nature remains neutral with regard to jurisdictional claims in published maps and institutional affiliations. 